\title{
Pathogenicity of Phytophthora $\times$ alni Isolates Obtained from Symptomatic Trees, Soil and Water against Alder
}

\author{
Aleksandra Trzewik*(D), Robert Maciorowski (D) and Teresa Orlikowska (D) \\ The National Institute of Horticultural Research, 96-100 Skierniewice, Poland; \\ robert.maciorowski@inhort.pl (R.M.); teresa.orlikowska@inhort.pl (T.O.) \\ * Correspondence: aleksandra.trzewik@inhort.pl; Tel.: +48-(0)4-6834-5506
}

check for updates

Citation: Trzewik, A.; Maciorowski, R.; Orlikowska, T. Pathogenicity of Phytophthora $\times$ alni Isolates Obtained from Symptomatic Trees, Soil and Water against Alder. Forests 2022, 13, 20. https://doi.org/10.3390/ f13010020

Academic Editors: Piotr Łakomy, Tomasz Oszako, Jolanta BehnkeBorowczyk, Lassaâd Belbahri and Jacek Piętka

Received: 30 November 2021 Accepted: 21 December 2021 Published: 23 December 2021

Publisher's Note: MDPI stays neutral with regard to jurisdictional claims in published maps and institutional affiliations.

Copyright: (c) 2021 by the authors. Licensee MDPI, Basel, Switzerland. This article is an open access article distributed under the terms and conditions of the Creative Commons Attribution (CC BY) license (https:// creativecommons.org/licenses/by/ $4.0 /)$.

\begin{abstract}
Phytophthora alni complex $(P . \times$ alni, $P . \times$ multiformis, $P$. uniformis $)$ are pathogens attacking alder seedlings and trees, causing significant losses in nurseries and natural tree stands. Decay of alder trees has been observed in Poland for over a dozen years. Overall, 25 Polish isolates of $P$. $\times$ alni obtained from symptomatic alder trunks, rhizosphere soil surrounding infected trees, and nearby natural streams were compared with isolates from symptomatic trunks obtained in France, Belgium and Hungary. Morphologic characterization of mycelium, vegetative and generative organs, temperature effect on mycelium growth, and their pathogenicity were studied. The mycelium growth rate of isolates from symptomatic plants was fastest on Carrot Agar (CA) medium, and from soil and water on Vegetable Agar (V8A) medium. The sizes of zoosporangia varied depending on their origin. The isolates that originated from the soil had the largest zoosporangia. The diameter of the oogonia and antheridia did not differ regardless of their origin. The results of pathogenicity tests of $P . \times$ alni isolates obtained from different sources showed that the soil isolates were the most aggressive in each test, followed by the isolates from the trunks and water. A simple test of leaf colonization can give an idea of the aggressiveness of the isolate towards the shoots and roots. No morphological or physiological markers of aggressiveness have been found.
\end{abstract}

Keywords: colonization of leaves; stems and seedlings; medium effect on growth rate and morphology; origin of Phytophthora $\times$ alni isolates affects pathogenicity

\section{Introduction}

The dieback of alder trees has been recorded in Europe since 1991, first in south-eastern France, but the causative agent of the disease was not identified at that time. The isolation of the pathogen initially referred to as alder Phytophthora was successful only in 1998 [1]. In the following years, alder Phytophthora was found on dying alder trees, mainly along rivers in southern England, and then in Wales [2-5] as well as in forest nurseries and on the areas of rivers and streams periodically flooded by water [6]. This alder disease has been found in several regions of the European continent [7-16]. The pathogens belonging to the P. alni complex attack primarily black alder (A. glutinosa) and to a lesser extent grey (A. incana) and heart-shaped (A. cordata) alders [4,6]. Since 2007, P. uniformis has also been isolated in Alaska and Oregon (USA) [17-19].

Initially, three subspecies of $P$. alni were distinguished on the basis of morphological, cytological, and genetic features: P. alni subsp. alni, P. alni subsp. uniformis and P. alni subsp. multiformis [20]. As a result of the analysis of nuclear and mitochondrial DNA and isozymes as well as the size of the genome, it was proved that P. alni subsp. alni is an allotriploid species, containing half the genomes of each parent taxa, i.e., P. alni subsp. uniformis and P. alni subsp. multiformis, which are diploid and allotetraploid, respectively [21]. Therefore, the names $P . \times$ alni, P. uniformis, and $P . \times$ multiformis have been adopted since 2015 . Since that period, the term $P$. alni complex species, which includes the three above-mentioned taxa, is currently used in the literature. 
In Poland, the dieback of black alder trees aged 5 to 90 years, growing along rivers, streams, lakes, and ponds, as well as in periodically flooded forest areas, has been observed since 1997 [22]. The first $P . \times$ alni isolate was obtained in 2002 from the base of a 15-year-old tree trunk [22]. Since $P . \times$ alni has been isolated many times, both from infected plants and the soil around the infected trees, as well as several riversides and forest sites, especially in the south-eastern part of the country [23-26]. The area affected by the alder disease was estimated at 6000 ha in 2006 [27].

The spread of alder Phytophthora disease is related to, inter alia, the use of river, stream, and canal water for irrigation of nurseries, which means that the pathogen can be transferred to forests or other permanent plantings on infected seedlings [7]. Symptoms of the disease on young alder seedlings are difficult to observe as poorly visible brightening on the youngest leaves, rarely slight necrosis of the collar, and slight browning of the root tips.

Due to the threats documented in the literature that the species of the P. alni complex, especially $P . \times a l n i$, pose to nurseries, forest stands, and riverside sites of alder, research was undertaken on the pathogenicity of $P . \times$ aln $i$ isolated in Poland from infected plants, rhizosphere and water near sick trees and confronting it with morphological and physiological characteristics of isolates.

\section{Materials and Methods}

\subsection{Isolates Used in the Study}

The research was carried out on 25 Polish isolates of P. $\times$ alni (Brasier \& S.A. Kirk) Husson, Ioos \& Marcais, nothosp. nov. isolated from infected black alder trunks (14 isolates numbered from PAA1 to PAA14), from rhizosphere soil surrounding diseased trees (4 isolates numbered from PAA15 to PAA18), and from the nearby natural streams (7 isolates numbered from PAA19 to PAA25). The isolates were collected in 2004-2006 according to the procedure described by Orlikowski et al. [22,28,29] in 14 sites in central and south-eastern Poland. Isolates from trees were collected from the bark of bleeding cankers. Briefly, inner bark pieces of approx. $10 \times 4 \times 5 \mathrm{~cm}$ were excised from the boundaries between the necrotic and healthy tissues of the trunks and transferred to the laboratory individually in plastic bags. The bark tissues were washed thoroughly in running tap water, flamed, trimmed into pieces of 3-5 $\mathrm{mm}^{2}$, placed on potato-dextrose agar (PDA, Difco, Detroit, USA) in $90 \mathrm{~mm}$ Petri dishes, with 8 pieces per dish, and incubated in the dark at $24^{\circ} \mathrm{C}$. The cultures were checked daily and presumptive Phytophthora colonies growing from the tissue pieces were cleaned by subsequent transfer onto PDA medium [22]. Soil samples were taken from at least 4 points around each diseased tree at $10-15 \mathrm{~cm}$ depth. The samples from under a sick tree (approx. $2 \mathrm{~kg}$ ) were mixed thoroughly, and $500 \mathrm{~g}$ sub-samples were flooded with 1.51 tap water. Leaves of 1-year old alder seedlings (A. glutinosa) grown in the greenhouse were placed on the water surface 10-12 per vessel as baits for Phytophthora isolation and incubated at $20{ }^{\circ} \mathrm{C}$ in the dark for 3-4 days. After that, washed and dried leaf blade parts were flamed, and 3-5 mm diam. fragments placed on PDA medium. Isolation $P . \times$ alni from water was carried out using A. glutinosa leaves as baits. The leaves in the punched bags were immersed in the streams flowing in the vicinity of diseased trees and left for 4-6 days, then placed in sterile plastic bags and transported to the laboratory. Washed and dried leaf blade parts were flamed, and 3-5 mm diam. fragments placed on PDA medium. Isolates $P . \times$ alni were identified on the basis of morphological features and PCR with primers designed by Ioos et al. [30]. Polish isolates were compared with isolates from infected alder trunks obtained in France (PAA26 and PAA27), Belgium (PAA28), and Hungary (reference isolate CBS 117375). Belgian isolate was kindly provided by Anne Chandelier, French isolates by Renaud Ioos, and Hungarian isolate was purchased from CBS-KNAW culture collection, Westerdijk Fungal Biodiversity Institute, Utrecht, Holland. The isolates were stored on PDA medium under sterile distilled water or sterile mineral oil in $1.5 \mathrm{~mL}$ tubes at $10{ }^{\circ} \mathrm{C}$ in the form of $0.3 \mathrm{~mm}$ discs cut from the sites of active growth of mycelium grown on the PDA medium. For regeneration, isolates were passaged on PDA or/and CA and incubated at $25{ }^{\circ} \mathrm{C}$. Before the tests, isolates were activated on alder 
seedlings. Briefly, 8-10 $\mathrm{cm}$ alder seedlings were punctured with the pointed end of a sterile scalpel and laid on wet cellulose paper. The place of puncture was covered with $3.5 \mathrm{~mm}$ diameter agar disks with mycelium and incubated at $22{ }^{\circ} \mathrm{C}$, and a photoperiod $12 / 12 \mathrm{~h}$ light/dark. After 5 days from the appearance of necrotic spots, $P . \times$ alni was re-isolated according to the procedure described above.

\subsection{Morphologic Characterization of Mycelium, Vegetative and Generative Organs and Effect of Temperature on Mycelium Growth}

The type of mycelium growth was characterized on PDA, V8A, and CA media. Observations included hyphae morphology, hyphae thickening, shape and size of zoosporangia and chlamydospores, and generative organs. Moreover, the growth rate of colonies at a temperature ranging from $5{ }^{\circ} \mathrm{C}$ to $35^{\circ} \mathrm{C}$ was measured daily. Releasing of zoospores was made according to the procedure described by Trzewik and Orlikowska [31]. Morphometric analyses of oogonia, antheridia, and oospores were made on 21-day old cultures, grown at $20^{\circ} \mathrm{C}$, on $\mathrm{CA}$ medium.

\subsection{Laboratory Tests of Pathogenicity}

Laboratory tests were carried out on leaf blades and shoot fragments of one-year-old shoots collected from several-year-old black alder seedlings and 11-12 cm alder seedlings in 2007-2008. Plant fragments and seedlings, before setting up the experiment, were washed in water with the addition of detergent, then rinsed in distilled water and dried with a sterile paper towel. Leaf-blades, fragments of shoots, and black alder seedlings, placed in cuvettes lined with moist filter paper and covered with a nylon mesh, were inoculated with $3 \mathrm{~mm}$ diameter CA medium discs overgrown with isolates. Sterile CA medium discs were the negative control. Leaf-blades and fragments of shoots were inoculated in the middle, avoiding the leaf veins. Black alder seedlings were inoculated the base of the shoot. One inoculation per one leaf or shoot was made. Before applying the disc, the plant material was gently punctured with a sterile preparation needle. Necrosis length was measured after 5 days of incubation at $23^{\circ} \mathrm{C}$. After the completion of the tests, the pathogens were re-isolated and their species affiliation was determined as below. The experiments were set up in 40 repetitions (40 seedlings and 40 leaves or shoots) and repeating them in two subsequent years. As the results were the same, the one-year averages are presented in the study $(n=40)$.

\subsection{Greenhouse Tests of Pathogenicity}

The experiments were carried out on 2-year-old black alder seedlings obtained from a forest nursery, planted in pots with a diameter of $8 \mathrm{~cm}$, filled with TS1 peat substrate (Klasmann-Deilmann). Plants were transplanted into $13 \mathrm{~cm}$ pots on 12 May and inoculated on 6 June. In the first experiment, seedlings were inoculated in 3 places: at the base of the shoot (approx. $2 \mathrm{~cm}$ from the ground), in the middle, and approx. $30 \mathrm{~cm}$ from the shoot tip, with CA medium discs with a diameter of $3 \mathrm{~mm}$ overgrown with the above-mentioned isolates ( 5 plants per isolate). The negative controls were plants inoculated with sterile agar discs. In the second experiment, 2-year-old alder seedlings were planted in a substrate infected with the aforementioned isolates. To obtain the inoculum, isolates were incubated for 7 days on Oat Meal Agar (OMA) at $23{ }^{\circ} \mathrm{C}$, homogenized, and mixed with the peat substrate in the proportion of 1 petri dish $(90 \mathrm{~mm}$ in diameter) with $1 \mathrm{~L}$ of TS1 peat substrate. After 7 days, $1 \mathrm{~L}$ of the infected substrate was mixed with $10 \mathrm{~L}$ of clean peat TS1. Twelve seedlings constitute one treatment (isolate). Two weeks after planting, pots were flooded with water in plastic containers to ensure conditions similar to those in which natural infestation occurs. After 3 days, the water was poured out and the plants were watered as needed until the end of the experiment. The greenhouse tests began in 2008.

The length of shoot necroses was measured at two-week intervals from June to October. In the first experiment, the averages of the lengths of three necroses were taken to analyze. Plants overwintered in a foil tunnel, and in early spring they were moved outside, and 
observations were carried out until the end of the growing season. At the end of the experiments, the root system was assessed, taking into account its size and the presence of necrotized roots. After the tests were completed, the pathogen was re-isolated from the stem fragments, roots, and substrate, and its identification was made on the basis of morphological features and PCR with primers designed by Ioos et al. [30].

\subsection{Re-Isolation of the Pathogen}

In the case of the laboratory experiments, fragments of approximately $2-3 \mathrm{~cm}$ in length were cut from the border of healthy and diseased tissues and disinfected in $70 \%$ ethyl alcohol solution for $1 \mathrm{~min}$. The alcohol was removed by rinsing three times with sterile distilled water and the collected fragments were dried with a sterile paper towel, and then, fragments of about $0.5 \mathrm{~cm}$ were placed on plates with a selective medium for Phytophthora PARP [32]. The plates were incubated at $23^{\circ} \mathrm{C}$ for $2-5$ days. During this time, the plates were examined daily under a microscope, and colony fragments with features resembling the genus Phytophthora spp. were laid out on PDA medium, then on CA medium for identification based on morphological features and liquid organic medium in the case of identification based on molecular markers. The pathogen was re-isolated from samples representing $10 \%$ of the experimental objects.

In greenhouse experiments, the pathogen was re-isolated both from the plant tissue (shoot, root) and from the substrate from all the objects. Before disinfection, the tissue fragments were rinsed under running tap water. Re-isolation from the substrate was carried out using the trap method, as described by Orlikowski et al. [28], using alder leaves as baits. Re-isolation of Phytophthora spp. from plants and the substrate was carried out successively as the plants died, and in the alders that were infected but not died, after the completion of the experiments.

\subsection{Statistical Analysis}

The obtained data were statistically analyzed using one-way analysis of variance and compared using the Tukey test at the significance level of $\alpha=0.05$. In order to determine the relationships resulting from: (i) the origin of the isolates, (ii) morphology, the principal components analysis (PCA) was done. For the analysis, the following characters were selected: radius of mycelium growth on the V8 medium at $25^{\circ} \mathrm{C}$, size of zoosporangia, length of necrosis on alder leaves (1st laboratory experiment), length of necrosis on shoots (2nd laboratory experiment), length of necrosis on infected seedlings shoot (3rd laboratory experiment), mean length of three necrosis on shoots of 2-year old seedlings inoculated with mycelium discs (1st greenhouse test), length of necrosis on shoots planted into the infected substrate (2nd greenhouse test). All calculations were done using the STATISTICA v. 13 software package (Dell Inc., Round Rock, TX, USA).

\section{Results}

\subsection{Morphology of Mycelium, and Vegetative and Generative Organs}

All isolates growing on PDA and V8 media formed white, fluffy aerial mycelium, denser at the inoculation site, and almost uniform with no distinct patterns. Some differences were observed on CA medium, on which isolates from diseased trees formed substrate hyphae but those from rhizosphere and water also formed aerial mycelium, similar to those from PDA and V8 media.

The hyphae were uniform, regardless of source and year of isolation; they were branched almost at right angles and divided by transverse walls. On all the media and in aqueous solutions, the hyphae had a smooth surface without nodules and lumps, and their width ranged from 5 to $6 \mu \mathrm{m}$. Zoosporangia were only formed on frozen pea medium, when placed in a non-sterile soil extract. They arose on simple sporangiophores, were ellipsoidal to egg-shaped, and were persistent. The sizes of zoosporangia varied depending on their origin. The isolates that originated from the soil had significantly larger zoosporangia $(55-67.5 \times 37-50 \mu \mathrm{m})$, the isolates from water were intermediate in size 
$(47.5-63 \times 28-43 \mu \mathrm{m})$, and the isolates from the symptomatic trunks were the smallest $(35-65 \times 24-50 \mu \mathrm{m})($ Table 1$)$. All tested isolates formed generative structures on agar media, most profusely on CA medium. Oogonia were ornamented and antheridia were predominantly two-celled and amphigynous. The diameter of the oogonia and antheridia did not differ regardless of their origin and year of isolation (data not shown).

Table 1. Dimension of zoosporangia of Phytophthora $\times$ alni isolates (in $\mu \mathrm{m})$.

\begin{tabular}{ccc}
\hline Isolates of $\boldsymbol{P} . \times$ alni & \multicolumn{2}{c}{ Dimensions of Zoosporangia $(\boldsymbol{\mu m}) \pm$ SD } \\
\cline { 2 - 3 }$($ Number of Isolates Measured) & Length & Width \\
\hline$P . \times$ alni obtained from alder trunks $(18)$ & $50.4^{1} \mathrm{c} \pm 7.64$ & $34.2 \mathrm{c} \pm 5.1$ \\
$P . \times$ alni obtained from soil $(4)$ & $62.0 \mathrm{a} \pm 6.47$ & $45.0 \mathrm{a} \pm 4.1$ \\
$P . \times$ alni obtained from water $(7)$ & $54.5 \mathrm{~b} \pm 6.23$ & $36.6 \mathrm{~b} \pm 4.1$ \\
\hline
\end{tabular}

${ }^{1}$ means in the columns, followed by the same letter, were not significantly different using Tukey's multiple range test at $p=0.05, \pm \mathrm{SD}$ (standard deviation).

\subsection{Growth of Mycelium Depending on Medium and Temperature}

The optimal growth temperature was $25^{\circ} \mathrm{C}$ for all isolates. The mycelium growth rate of isolates from symptomatic plants was fastest on the CA medium, while the growth rate of isolates from soil and water was faster on V8A than on PDA or CA. Growth was very poor on the PDA medium regardless of the origin of the isolates (Table 2).

Table 2. Effect of medium on daily growth of Phytophthora $\times$ alni isolates at $25^{\circ} \mathrm{C}$.

\begin{tabular}{cccc}
\hline Isolates of $\boldsymbol{P} . \times$ alni & \multicolumn{3}{c}{ Daily Growth of Hyphae at $\mathbf{2 5}{ }^{\circ} \mathbf{C}(\mathbf{m m} / \mathbf{2 4} \mathbf{~ h})$} \\
\cline { 2 - 4 } (Number of Isolates Evaluated) & PDA & V8 & CA \\
\hline$P . \times$ alni obtained from alder trunks (18) & $3.82{ }^{1} \mathrm{c} \pm 0.19$ & $6.81 \mathrm{~b} \pm 0.23$ & $9.48 \mathrm{a} \pm 0.14$ \\
$P . \times$ alni obtained from soil (4) & $3.86 \mathrm{c} \pm 0.20$ & $9.11 \mathrm{a} \pm 0.26$ & $7.11 \mathrm{~b} \pm 0.26$ \\
$P . \times$ alni obtained from water (7) & $3.78 \mathrm{c} \pm 0.21$ & $9.14 \mathrm{a} \pm 0.32$ & $7.11 \mathrm{~b} \pm 0.33$ \\
\hline
\end{tabular}

${ }^{1}$ means for the types of media, followed by the same letter, were not significantly different using Tukey's multiple range test at $p=0.05, \pm \mathrm{SD}$ (standard deviation).

\subsection{Laboratory Tests}

The isolates retrieved from the rhizosphere were the most virulent in the laboratory tests, while the isolates from water were the least virulent, regardless of the plant tissue. Isolates from infected plants Polish, French and Hungarian had the same level of ability to colonize. Only the Belgian isolate showed a lower virulence (Figure 1). The largest necroses on the 5th day were observed on seedlings, intermediate on shoot fragments, while the smallest were on leaf-blades. The differences between isolates from different sources were significant at $p=0.05$, and between replicates in the same group were not significant.

\subsection{Greenhouse Tests}

The largest necroses on seedling shoots that were inoculated with mycelium discs were characteristic of Polish isolates from soil and French isolate from plants (Figure 2). Already after one month, the necrotic lesions were $40 \mathrm{~cm}$ long. Within the next three months, all seedlings inoculated with these isolates died (Figures 2 and 3). Polish and Hungarian isolates from plants caused necroses of $6-7 \mathrm{~cm}$, and Polish isolates from water only of $3 \mathrm{~cm}$ within one month. After the next three months, necrotic lesions caused by Polish isolates from trunks were $23 \mathrm{~cm}$ long, and by Hungarian isolates $34 \mathrm{~cm}$ long, while the isolates from water only $7 \mathrm{~cm}$ long. In the next seven months, all seedlings infected with Hungarian isolate died. Total mortality was also caused by three of Polish isolates from trunks. Within the next four months, all plants that were infected with other four Polish isolates from trunks died. The remaining plants survived through 15 months of the experiment, although all have longer or shorter necrotic lesions (Figure 2 and Supplementary Materials Table S1). 


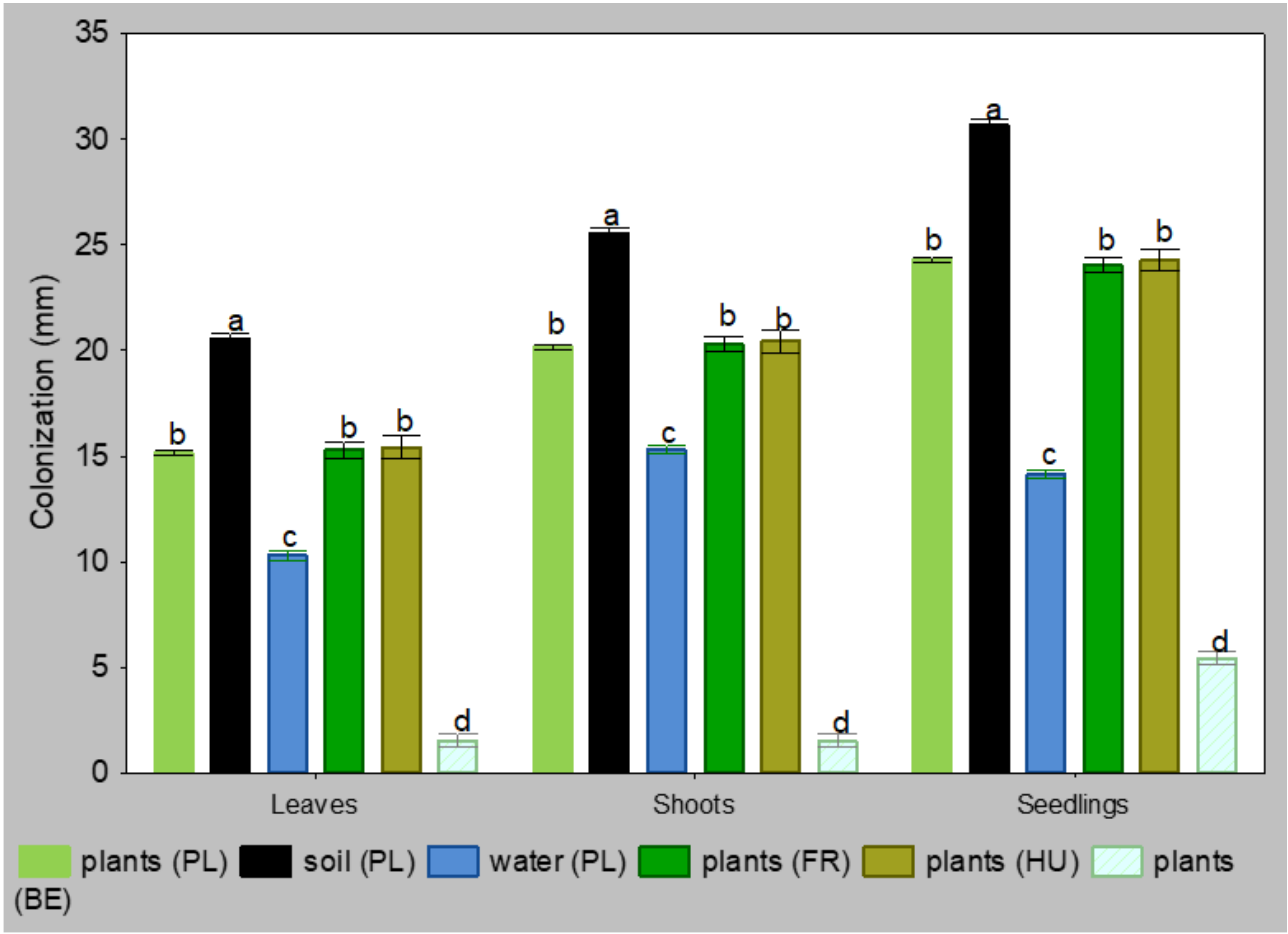

Figure 1. Colonization of leaves, shoots and seedlings of Alnus glutinosa by isolates Phytophthora $\times$ alni 5 days after inoculation $(n=40$, means $\pm \mathrm{SD})$. Means in the columns, followed by the same letter, were not significantly different using Tukey HSD test at $p=0.05$.

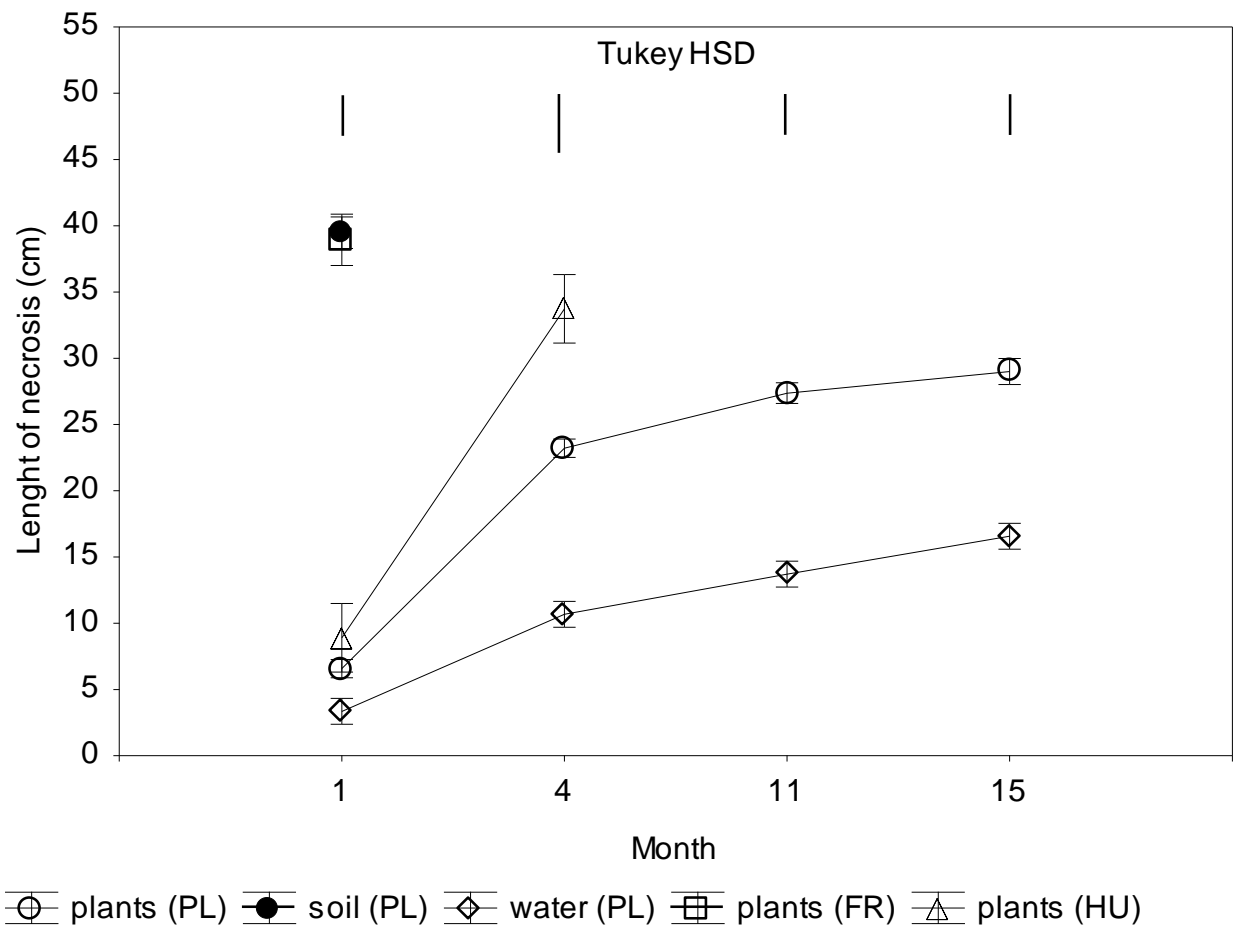

Figure 2. Colonization of shoots 2-year-old seedlings of Alnus glutinosa inoculated with Phytophthora $\times$ alni $(n=15)$. Vertical bars at means showing SD. Tukey HSD-honestly significant difference calculated according to Tukey test at $p=0.05$ for comparisons of the isolates group at each term of measurements. 

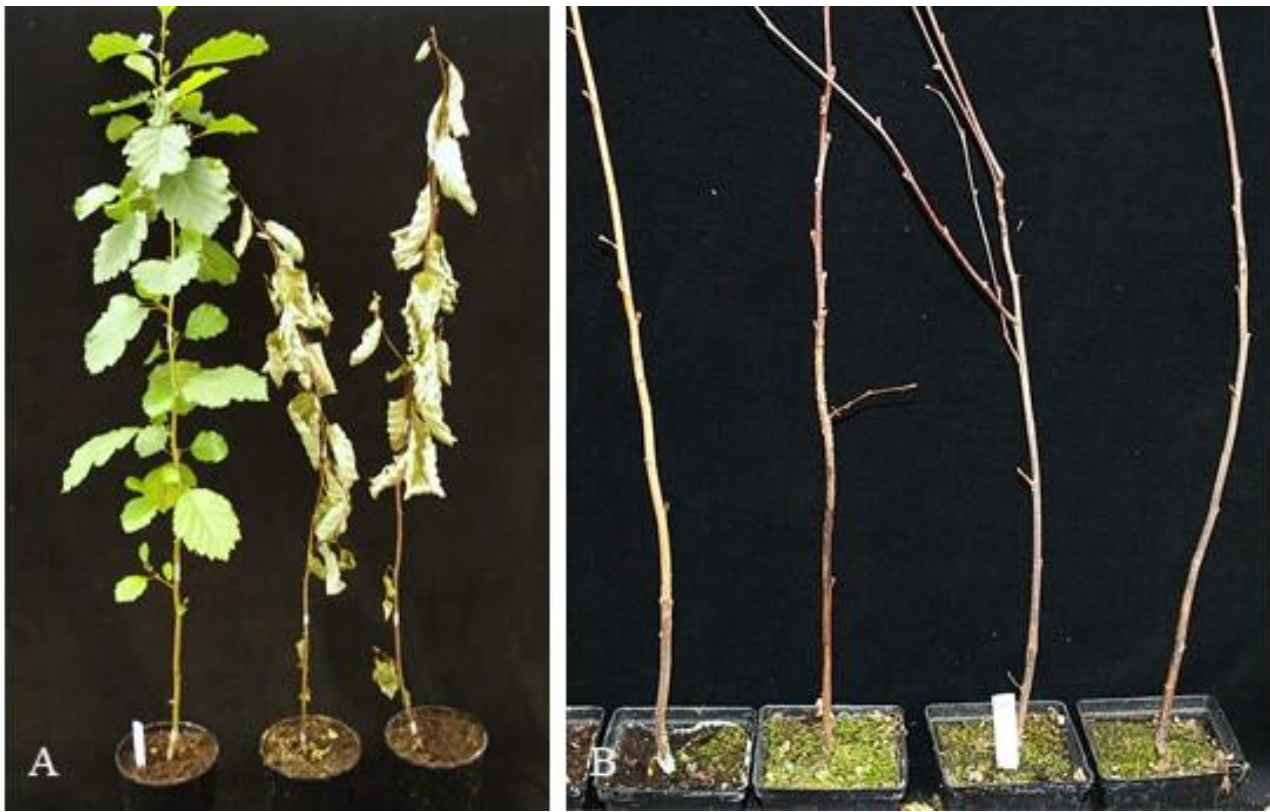

Figure 3. (A) Dead plants 8 weeks after inoculation with mycelium disc of 2-year-old alder seedlings with Polish isolate $P . \times$ alni PAA16 from soil; on the left control not inoculated; (B) Dead alder seedlings planted in infected substrate with isolate $P . \times$ alni PAA 16 from soil 8 weeks after inoculation.

Infection via the infected substrate was less oppressive for the seedlings. The mean necroses length caused by Polish isolates from diseased trunks was $25-27 \mathrm{~cm}$ after 11 and 15 months, respectively, which was similar to the necroses caused by Belgic and Hungarian isolates. Necroses caused by isolates from water were about twice smaller (Figure 4 and Supplementary Materials Table S2). None of the plants infected with these above isolates died during the 15 months of the experiment. The most aggressive were Polish isolates from soil and French isolates from plants. After one month, necroses caused by these isolates were 25 and $30 \mathrm{~cm}$ long, and 35 and $46 \mathrm{~cm}$ long after four months. All plants from this group died within the next seven months (Figures $3 \mathrm{~B}$ and 4 and Table S2). The least aggressive were isolates from water; after 15 months, necroses were only about $10 \mathrm{~cm}$ long.

\subsection{Re-Isolation of the Pathogen}

After completion of the laboratory tests, the pathogenic factors were re-isolated from necroses on leaves, cut shoots, and shoots of seedlings from all isolates except for the Belgian isolate PAA28 and the negative control. In a greenhouse experiment in which inoculation was made on stems, pathogens were re-isolated from all shoots, and from roots and substrate only in the cases from French isolates and when isolates were retrieved from soil. Pathogens were isolated from the shoots, roots and substrate of all the plants, from seedlings grown in a contaminated substrate (Supplementary Materials Table S3).

\subsection{PCA Analysis}

Based on PCA, it was stated that the variability between isolates from different sources was high, but lower between isolates from the same source (Figure 5). Laboratory pathogenicity tests are strongly and significantly correlated with greenhouse tests on 2-year-old alder seedlings. The most severe symptoms, both in the laboratory and greenhouse tests, were observed in the case of soil-derived isolates, and the lowest waterderived isolates. 


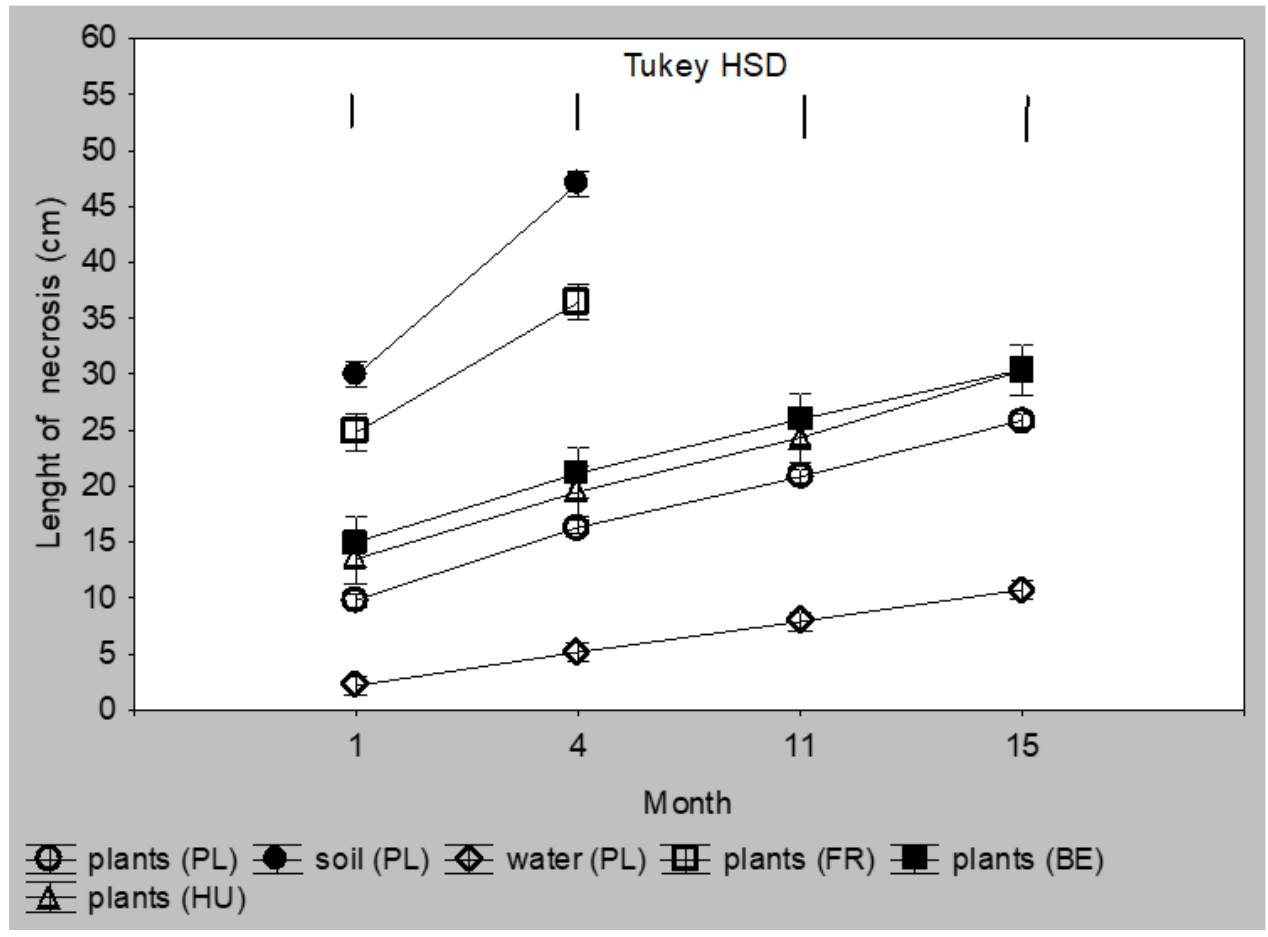

Figure 4. Colonization of Alnus glutinosa shoots planted as 2-year-old seedlings in a substrate infected with Phytophthora $\times$ alni $(n=12)$. Vertical bars at means showing SD. Tukey HSD—honestly significant difference calculated according to Tukey test at $p=0.05$ for comparisons of the isolates group at each term of measurements.

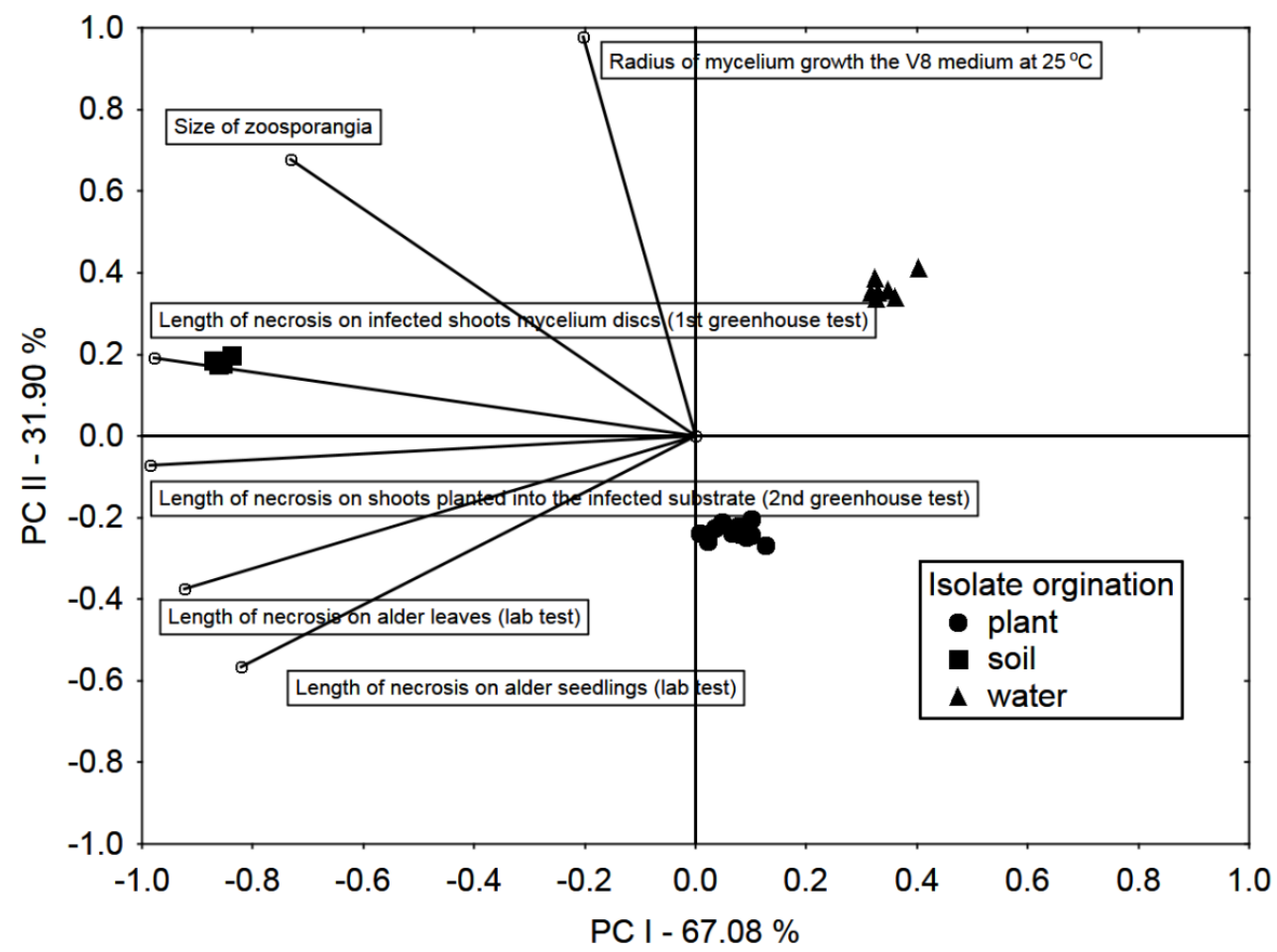

Figure 5. Principal Component analysis (PCA) biplot in the arrangement of the first two principal components PC I and PC II. Vectors and symbols representing, testing methods and isolate origin, respectively. 


\section{Discussion}

Mass dieback of alder caused by Phytophthora spp. has become a serious problem in many tree stands in Europe and the USA [33]. The disease spreads epidemically mainly after flooding and with running water, and mass infection is particularly high after a period of drought in these areas [34]. A massive episodic alder decline also occurred in the distant past in Northern Europe. It was discovered that in lake sediments and boreal forest hollows, an instant decline in Alnus pollen in southern Finland was noticed [35]. These layers were dated AD 600-1000. The authors suggested possible reasons caused by long-lasting drought period and/or fungal disease compared to the ongoing Phytophthora outbreak. Jung et al. [33] described how an epidemic-type alder infection in some parts of Germany was the reason for the unintended consequence of the accidental planting of infected Alnus trees to harden slopes and riverbanks and as the afforestation of postagricultural and wet forest areas. Chemical control of pathogens in the natural environment is practically impossible, and the only rational prevention is the use of healthy nursery plants, including those clonally propagated [36]. Jung et al. [34] indicate the necessity of planting alder genotypes of higher resistance to P. alni root rot. Štochlová et al. [37] studied the susceptibility of 90 black alder genotypes from different $C$ zech regions against two isolates of $P$. $\times$ alni, observing infections on cut fragments of branches and recorded the area of necrotic lesions on phloem parts. A great variability between genotypes and isolates was observed in that experiment. An additional variability resulted from a geographical position. More resistant genotypes were more frequent in the southwestern part of the study region and at lower altitudes.

Pathogens belonging to Phytophthora alni complex are not the only Oomycetes causing phytophthorosis symptoms on alder trees. From symptomatic alder trees, 17 genera and species of Phytophthora were isolated in Poland; the most common of which was P. alni [38]. In another study, 68 Phytophthora isolates were obtained from diseased alder trunks and the surrounding rhizosphere in the east-southern part of Poland [26]. From symptomatic trees were isolated: $P . \times$ alni, P. cambivora, P. cactorum, P. plurivora, P. megasperma, P. pseudosyringae, and $P$. syringae. The most aggressive in the colonization of alder leaves and 1-year stems were P. alni and P. plurivora. Bregant et al. [39] reported that out of 232 isolates obtained in northern Italy from symptomatic black, grey and green alder trunks, rhizosphere, and nearby water, 12 Phytophthora species were isolated, including P. plurivora, P. pseudocryptogea, and P. hydropathica as the most common; none of the isolates was identified as belonging to the P. alni complex.

The large number of $P . \times a l n i$ isolates obtained from three different sources in Poland raises the question of the level of their aggressiveness against black alder. We studied this issue using five pathogenicity tests: inoculation of leaves, stems, 3-month-old seedlings in the laboratory, and two tests on 2-year-old seedlings in the greenhouse. The 2-year-old seedlings were tested by the inoculation of shoots or roots. In the laboratory tests, there were significant differences in lesion sizes between isolates from different sources after 5 days, while differences between isolates of the same source were not significant. However, within one and four months in the greenhouse, the differences between the isolates originating from the trunks became significant, and those causing the longest necrotic lesions were lethal to plants in the following months. In the treatment in which seedlings were planted in an infested peat substrate, differences in the length of lesions on the shoots were also observed in the first month. Still, they were smaller in the subsequent terms of observation compared to the treatment in which the shoots were inoculated. Although the plants suffered from the pathogen, they did not die until the end of the experiment, which can be explained by the ability to regenerate the roots, replace diseased roots with healthy ones, and block pathogen movement along the trunk. Mortality was caused only by soil and French isolates from diseased trees. In all tests, soil isolates were the most aggressive and water isolates were the least aggressive. From our results, it can be concluded that large differences in aggressiveness are easily manifested already on the leaves in a laboratory, and 
this simple and short test may reflect the degree of aggressiveness of the isolates towards seedlings.

The results of infection of alder with P. alni complex depend on several factors: type of inoculated organ [40,41], method of inoculation [40], environment condition [42], derivation of isolate-host genotype, geographic provenience [37], and, as was shown in our study, from what source the isolates were obtained-diseased trunks or soil from under these trees.

Chandelier et al. [41] evaluated various inoculation methods for screening black alder resistance to $P$. alni isolates obtained from symptomatic trunks. The infection was carried out on cut shoots, on shoots in situ, and on 2-year-old seedlings. The length of the lesions showed no differences in aggressiveness between the 10 isolates. Nevertheless, a 2-, 3-, or 4-fold difference in sporulation between five isolates was detected. In the above study, the most important was the inoculation period and genotype of the alder. The greatest aggressiveness was recorded on plants inoculated from July to September. In our experiments, we tested the aggressiveness of isolates of various origins on leaves, scions, and the whole seedlings derived from the same nursery, which means that the explants used for the tests came from the same place and were genetically similar. For the greenhouse tests, the plants were inoculated in June. Zamora-Ballesteros et al. [43] analyzed the pathogenicity of $P . \times$ alni, $P . \times$ multiformis, $P$. uniformis, and $P$. plurivora isolates against 1-year-old $A$. glutinosa seedlings inoculated with mycelium plugs on stems. All isolates caused mortality of seedlings. The most lethal (50\%) isolates were P. plurivora, followed by $P . \times$ multiformis and P. uniformis. $P . \times$ alni isolates differed in lethality (20-30\%) when analyzed for 37 weeks. In the above experiment, the longest lesions on shoots were made by $P$. $\times$ multiformis, while the lesions caused by $P . \times$ alni and $P$. uniformis isolates did not differ significantly.

It would be valuable to find any morphological marker connected with the isolate aggressiveness. $P . \times$ alni mycelium is homogenous and does not form patterns. At the temperature of $25^{\circ} \mathrm{C}$, which was optimal for all isolates, no differences were found in the growth rate of mycelium on the PDA medium, but on V8 the highest daily growth was shown by soil and water isolates, and on CA medium, the greatest growth rate increase was recorded for trunk isolates (Table 2). Trunk isolates formed substrate-type mycelium, while those isolated from soil and water, air-type ones on CA medium. There were also differences between zoosporangia sizes. The largest of them were soil isolates, then water isolates and the smallest zoosporangia were trunk isolates. It might be presumed that larger zoosporangia form more zoospores, but this interpretation does not reflect the differences in lower pathogenicity of water-derived isolates.

The genus Phytophthora is very diverse. There are known such species as P. cinnamomi attacking over 5000 plant species [44] and specialized ones as $P$. $\times$ alni. Still, the key genes and markers of pathogenicity are not known in P. cinnamomi [45] despite intensive research [46]. According to this author, the differences in pathogenicity of P. cinnamomi isolates can be recognized to some extent based on microsatellite fingerprint groups. A study by Kasuga et al. [47] on the pathogenicity of P. ramorum revealed diversity in colony morphology, virulence, and the tendency to senescence. The morphology and senescence were associated with the host species from which the given isolate was obtained but virulence with the geographical place of origin, that pointed on climatic factors. These statements may be useful to partially explain our results. The rhizosphere environment can permanently stimulate virulence, while the aquatic environment (especially if the isolates were not from the closest vicinity of the diseased trees) can permanently block it. In a study by Haque et al. [40] on the pathogenicity of $P$. alni subspecies isolated from symptomatic trees it was shown that virulence to A. glutinosa depends on the temperature at which the inoculation was performed and the manner of leaf wounding, but not on the isolate source or subspecies. Linde et al. [48] studied the age of $P$. cinnamomi isolates in relation to their virulence. Cultures older than one or two decades formed colonies with a diameter twice smaller and caused much less damage to Eucalyptus smithii shoots under field conditions than younger isolates. The authors do not report whether the cultures were rejuvenated 
before the experiment. In our case, the Polish isolates were roughly the same age (collected in 2004-2006), while isolates obtained from France and Belgium were collected in 2003 and 2001, respectively. The year of isolation of the CBS isolate is unknown. Moreover, all isolates were rejuvenated and passaged on alder seedlings before the experiment. Therefore, the age-related virulence factor of the isolates may be negligible in our study.

As far as we know, the level of pathogenicity related to the origin of the $P$. $\times$ alni from soil and water compared to trunk isolates has not yet been investigated, and this issue needs further study.

\section{Conclusions}

The results of three pathogenicity tests of Phytophthora $\times$ alni isolates were performed in the laboratory on black alder leaves, shoots, and seedlings and two tests made in the greenhouse on 2-year-old seedlings showed that the soil isolates were the most aggressive in each test, followed by the stem and water isolates. Therefore, a simple test of leaf colonization can give an idea about the aggressiveness of the isolate towards the shoots and roots.

Supplementary Materials: The following are available online at https:/ / www.mdpi.com/article/ 10.3390/f13010020/s1, Table S1: Colonization of shoots 2-year-old seedlings of Alnus glutinosa inoculated on shoots with Phytophthora $\times$ alni $(n=15)$. Darkened fields indicate dead plants; Table S2: Colonization of Alnus glutinosa shoots planted as 2-year-old seedlings in a substrate infected with Phytophthora $\times$ alni $(n=12)$. Darkened fields indicate dead plants; Table S3: Re-isolation of Phytophthora $\times$ alni species in greenhouse experiments.

Author Contributions: Conceptualization, A.T. and T.O.; methodology, A.T. and T.O.; formal analysis, A.T. and R.M.; investigation, A.T.; data curation, A.T. and T.O.; writing-original draft preparation, A.T. and T.O.; writing-review \& editing, T.O. and A.T.; visualization, A.T. and R.M.; supervision, T.O.; project administration, A.T. and T.O.; funding acquisition, A.T. All authors have read and agreed to the published version of the manuscript.

Funding: The study was funded by the Polish Ministry of Science and Higher Education through statutory funds (P 26) of The National Institute of Horticultural Research, Skierniewice, Poland.

Institutional Review Board Statement: Not applicable.

Informed Consent Statement: Not applicable.

Data Availability Statement: Not applicable.

Acknowledgments: The authors would like to thank Leszek B. Orlikowski for donation of Phytophthora $\times$ alni isolates and Lucyna Ogórek for her excellent technical work.

Conflicts of Interest: The authors declare no conflict of interest.

\section{References}

1. Streito, J.-C.; Legrand, P.; Tabary, F.; Jarnouen de Villartay, G. Phytophthora disease of alder (Alnus glutinosa) in France: Investigation between 1995 and 1999. For. Pathol. 2002, 32, 179-191. [CrossRef]

2. Brasier, C.M.; Rose, J.; Gibbs, J.N. An unusual Phytophthora associated with widespread alder mortality in Britain. Plant Pathol. 1995, 44, 999-1007. [CrossRef]

3. Brasier, C.M.; Cooke, D.E.L.; Duncan, J.M. Origin of a new Phytophthora pathogen through interspecific hybridization. Proc. Natl. Acad. Sci. USA 1999, 96, 5878-5883. [CrossRef] [PubMed]

4. Gibbs, J.N.; Lipscombe, M.A.; Peace, A.J. The impact of Phytophthora disease on riparian populations of common alder (Alnus glutinosa) in southern Britain. Eur. J. For. Pathol. 1999, 29, 39-50. [CrossRef]

5. Streito, J.-C.; Gibbs, J.N. Alder Phytophthora in France and the United Kingdom: Symptoms, isolation methods, distribution, and damage. In Phytophtora Diseases of Forest Trees, Corvallis, Oregon, USA, 30.08-03.09.1999; Hansen, E.M., Sutton, W., Eds.; Oregon State University: Corvallis, OR, USA, 2000; pp. 37-39.

6. Gibbs, J.N. Phytophthora root disease of alder in Britain. Bull. OEPP/EPPO Bull. 1995, 25, 661-664. [CrossRef]

7. Jung, T.; Blaschke, M. Phytophthora root and collar rot alders in Bavaria: Distribution, modes of spread and possible management strategies. Plant Pathol. 2004, 53, 197-208. [CrossRef]

8. Cech, T.; Hendry, S. A review of diebacks and declines of alder (Alnus spp.) in Europe. For. Comm. Bull. 2003, $126,15-24$. 
9. De Gruyter, J.; Man In't Veldt, W.A. Phytophthora disease of alder. Ann. Rep. Plant Prot. Ser. Neth. 2000, 85-94.

10. Szabó, I.; Nagy, Z.; Bakonyi, J.; Érsek, T. First report of Phytophthora root and collar rot of alder in Hungary. Plant Dis. 2000, 84, 1251. [CrossRef] [PubMed]

11. Webber, J.; Gibbs, J.; Hendry, S. Phytophthora Disease of Alder; Forestry Commission: Edinburgh, UK, 2004.

12. Černý, K.; Gregorová, B.; Holub, V.; Strnadová, V. First finds of 'alder Phytophthora' in the Czech Republic. Czech Mycol. 2003, 55, 291-296. [CrossRef]

13. Santini, A.; Barzanti, G.P.; Capretti, P. A new Phytophthora root disease of alder in Italy. Plant Dis. 2001, 85, 560. [CrossRef] [PubMed]

14. Varela, C.P.; Martinez, C.R.; Vázquez, J.P.M.; Casal, O.A. First report of Phytophthora rot on alders caused by Phytophthora alni subsp. alni in Spain. Plant Dis. 2010, 94, 273. [CrossRef] [PubMed]

15. Solla, A.; Pérez-Sierra, A.; Corcobado, T.; Haque, M.M.; Diez, J.J.; Jung, T. Phytophthora alni on Alnus glutinosa reported for the first time in Spain. Plant Pathol. 2010, 59, 798. [CrossRef]

16. CABI/EPPO. Phytophthora Alni [Distribution Map]. Distribution Maps of Plant Diseases, 1st ed.; CABI: Wallingford, UK, 2008.

17. Adams, G.C.; Catal, M.; Trummer, L.; Hansen, E.M.; Reeser, P.; Worrall, J.J. Phytophthora alni subsp. uniformis found in Alaska beneath thinleaf alders. Plant Health Prog. 2008, 9, 38. [CrossRef]

18. Adams, G.C.; Catal, M.; Trummer, L. Distribution and severity of alder Phytophthora in Alaska. In Proceedings of the Sudden Oak Death Fourth Science Symposium, Santa Cruz, CA, USA, 15-18 June 2009.

19. Sims, L.L.; Sutton, W.; Reeser, P.; Hansen, E.M. The Phytophthora species assemblage and diversity in riparian alder ecosystem of western Oregon, USA. Mycologia 2015, 107, 889-902. [CrossRef]

20. Brasier, C.M.; Kirk, S.A.; Delcan, J.; Cooke, D.E.L.; Jung, T.; Man In't Veldt, W.A. Phytophthora alni sp. nov. and its variants: Designation of emerging heteroploid hybrid pathogens spreading on Alnus trees. Mycol. Res. 2004, 108, 1172-1184. [CrossRef] [PubMed]

21. Husson, C.; Aguayo, J.; Revellin, C.; Frey, P.; Ioos, R.; Marçais, B. Evidence for homoploid speciation in Phytophthora alni supports taxonomic reclassification in this species complex. Fungal Genet. Biol. 2015, 77, 12-21. [CrossRef]

22. Orlikowski, L.B.; Oszako, T.; Szkuta, G. First record of alder Phytophthora in Poland. J. Plant Prot. Res. 2003, 43, 33-39.

23. Oszako, T.; Orlikowski, L.B. Phytophthora alni as the main cause of the alder decline in Poland. Prog. Plant Prot. 2005, 45, 343-350. (In Polish)

24. Oszako, T. The usefulness of traps and PDA medium for Phytophthora alni isolation from infected tissues and soil. Sylwan 2006, 150, 59-64. (In Polish)

25. Trzewik, A.; Orlikowska, T.; Oszako, T. The threat by Phytophthora alni of alder (Alnus glutinosa) in Poland. Adv. Agric. Sci. Probl. Iss. 2008, 529, 227-233. (In Polish)

26. Trzewik, A.; Orlikowski, L.B.; Oszako, T.; Nowakowska, J.A.; Orlikowska, T. The characterization of Phytophthora isolates obtained from diseased Alnus glutinosa in Poland. Balt. For. 2015, 21, 44-50.

27. Oszako, T. Contribution of Phytophthora spp. in the phenomenon of alder decline in Poland. Phytopathol. Pol. 2010, 57, 53-62.

28. Orlikowski, L.B.; Oszako, T.; Szkuta, G. First record of Phytophthora spp. associated with the decline of European beech stand in south-west Poland. Phytopathol. Pol. 2006, 42, 37-46.

29. Orlikowski, L.B.; Trzewik, A.; Orlikowska, T. Water as potential source of Phytophthora citricola. J. Plant Prot. Res. 2007, 47, 125-132.

30. Ioos, R.; Husson, C.; Andrieux, A.; Frey, P. SCAR-Based PCR primers to detect the hybrid pathogen Phytophthora alni and its subspecies causing alder disease in Europe. Eur. J. Plant Pathol. 2005, 112, 323-335. [CrossRef]

31. Trzewik, A.; Orlikowska, T. Detection and identification of Phytophthora alni. Commun. Agric. Appl. Biol. Sci. Ghent Univ. 2010, 75, 655-658.

32. Kannwischer, M.E.; Mitchell, D.J. The influence of a fungicide on the epidemiology of black shank of tabacco. Phytopathology 1978, 68, 1760-1765. [CrossRef]

33. Jung, T.; Downing, M.; Blaschke, M.; Vernon, T. Phytophthora root and collar rot of alders caused by the invasive Phytophthora alni: Actual distribution, pathways, and modeled potential distribution in Bavaria. In Alien Invasive Species and International Trade; Evans, H., Oszako, T., Eds.; Forest Research Institute: Warsaw, Poland, 2007; pp. 10-18.

34. Jung, T.; Pérez-Sierra, A.; Durán, A.; Jung, M.H.; Balci, Y.; Scanu, B. Cancer and decline diseases caused by soil- and airborne Phytophthora species in forests and woodlands. Persoonia 2018, 40, 182-220. [CrossRef]

35. Stivrins, N.; Buchan, M.S.; Disbrey, H.R.; Kuosmanen, N.; Latalowa, M.; Lempinen, J.; Muukkonen, P.; Slowinski, M.; Veski, S.; Seppa, H. Widespread, episodic decline of alder (Alnus) during the medieval period in the boreal forest of Europe. J. Quat. Sci. 2017, 32, 903-907. [CrossRef]

36. San Jose, M.C.; Cernadas, M.J.; Janeiro, L.V.; Blazquez, N.; Mosteiro, F.; De Anta, A.; De Castro, E.; Cuenca, B. In Vitro propagation of tolerant alders for the conservation of riverbanks. Study of their resistance to Phytophthora alni. In Perspectivas del Aqua. Investigación, Gestión, y Valores del Aqua en el Mundo Actual; Alvarez-Valasquez, M.A., De Una-Alvarez, E., Coordinatores; Dykinson: Madrid, Spain, 2019; pp. 103-110, ISBN 978-84-1324-549-2.

37. Štochlová, P.; Novotná, K.; Černý, K. Variation in Alnus glutinosa susceptibility to Phytophthora $\times$ alni infection and its geographic pattern in the Czech Republic. For. Pathol. 2016, 46, 3-10. [CrossRef]

38. Oszako, T. Alder decline in Poland. In Proceedings of the IUFRO Working Party Diseases and Insects in Forest Nurseries, the Sixth Meeting, Uherské Hradiště, Czech Republic, 11-14 September 2007; pp. 129-137. 
39. Bregant, C.; Sanna, G.P.; Bottos, A.; Maddau, L.; Montecchio, L.; Linaldeddu, B.T. Divesity and pathogenicity of Phytophthora species associated with declining alder trees in Italy and description of Phytophthora alpine sp. nov. Forests 2020, 11, 848. [CrossRef]

40. Haque, M.M.; Martin-Garciá, J.; Diez, J.J. Variation in pathogenicity among the three subspecies of Phytophthora alni on detached leaves, twigs and branches of Alnus glutinosa. For. Pathol. 2015, 45, 484-491. [CrossRef]

41. Chandelier, A.; Husson, C.; Druart, P.; Marcais, B. Assessment of inoculation methods for screening black alder resistance to Phytophthora $\times$ alni. Plant Pathol. 2016, 65, 441-450. [CrossRef]

42. Štochlová, P.; Novotná, K.; Černý, K. Factors affecting the development of Phytophthora alni spp. alni infections in Alnus glutinosa L. J. For. Sci. 2012, 58, 123-130. [CrossRef]

43. Zamora-Ballesteros, C.; Haque, M.M.U.; Diez, J.J.; Martin-Garcia, J. Pathogenicity of Phytophthors alni complex and P. plurivora in Alnus glutinosa seedlings. For. Pathol. 2017, 47, e12299. [CrossRef]

44. Engelbrecht, J.; Duong, T.A.; Prabhu, S.A.; Seedat, M.; van den Berg, N. Genome of the destructive oomycete Phytophthora cinnamomi provides insights into its pathogenicity and adaptive potential. BMC Genomi. 2021, 22, 302. [CrossRef] [PubMed]

45. De Andrade Lourenco, D.; Branco, J.; Choupina, A. Phytopathogenic oomycetes: A review focusin on Phytophthora cinnamomi and biotechnological approaches. Mol. Biol. Rep. 2020, 47, 9179-9188. [CrossRef] [PubMed]

46. Eggers, J.E. Variation among Phytophthora cinnamomi isolates from oak forest soils in the Eastern United States. Plant Dis. 2012, 96, 1608-1614. [CrossRef] [PubMed]

47. Kasuga, T.; Kozanitas, M.; Bui, M.; Huberli, D.; Rizzo, D.M.; Garbelotto, M. Phenotypic diversification is associated with host-induced transposon derepression in the sudden oak death pathogen Phytophthora ramorum. PLoS ONE 2012, 7, e34728. [CrossRef]

48. Linde, C.; Kemp, G.H.J.; Wingfield, M.J. Variation in pathogenicity among South African isolates of Phytophthora cinnamomi. Eur. J. Plant Pathol. 1999, 105, 231-239. [CrossRef] 